\title{
CYP19 gene variant confers susceptibility to endometriosis-associated infertility in Chinese women
}

\author{
Ledan Wang, Xiaosheng Lu, Danhan Wang, Wanglei Qu, Wenju Li, Xiaowen Xu, Qiusui Huang, Xueying Han \\ and Jieqiang Lv
}

An aromatase encoded by the CYP19 gene catalyzes the final step in the biosynthesis of estrogens, which is related to endometriosis development. To assess the association of CYP19 gene polymorphisms with the risks of endometriosis, chocolate cysts and endometriosis-related infertility, a case-control study was conducted in Chinese Han women by recruiting 225 healthy control females, 146 patients with endometriosis, 94 endometriosis women with chocolate cyst and 65 women with infertility resulting from endometriosis, as diagnosed by both pathological and laparoscopic findings. Individual genotypes at rs2236722:T > C, rs700518:A > G, rs10046:T > C and [TTTA]n polymorphisms were identified. Allelic and genotypic frequencies were compared between the control group and case groups by chi-square analysis. Odds ratios (ORs) and $95 \%$ confidence intervals $(95 \% \mathrm{Cls})$ were determined by logistic regression analysis to predict the association of CYP19 gene polymorphisms with the risk of endometriosis, the related chocolate cysts and infertility. The genotype distributions of the tested CYP19 gene polymorphisms were not significantly different between the healthy control group and the endometriosis/ endometriosis with the chocolate cyst group. However, the CYP19 rs700518AA genotype was significantly associated with an increased risk of endometriosis-related infertility $(55.4 \%$ in the infertility group vs $25.3 \%$ in the control group, $P<0.001$; OR $(95 \% \mathrm{Cl}): 3.66(2.06-6.50))$ under the recessive form of the A allele. Therefore, we concluded that in Chinese Han females CYP19 gene polymorphisms are not associated with susceptibility to endometriosis or chocolate cysts, whereas CYP19 rs700518AA genotype confers genetic susceptibility to endometriosis-related infertility.

Experimental \& Molecular Medicine (2014) 46, e103; doi:10.1038/emm.2014.31; published online 27 June 2014

Keywords: CYP19; endometriosis; infertility; single-nucleotide polymorphism

\section{INTRODUCTION}

Endometriosis is a chronic gynecological disorder defined as the presence and growth of endometrial cells outside of the uterus, and it affects approximately $10 \%$ of women of reproductive age. ${ }^{1}$ Endometriosis manifests as severe pelvic pain, dysmenorrhea and bladder/bowel discomfort and accounts for $30-50 \%$ of infertility cases. Ovarian chocolate cysts and adenomyosis also frequently accompany endometriosis. ${ }^{2,3}$

Historically, the well-known mechanism of endometriosis can be tracked to Sampson's Theory of the Etiology of Endometriosis in 1927, which proposed that the development of endometriosis is characterized by the implantation of endometrial tissue on the peritoneum through retrograde menstruation. ${ }^{4}$ However, because $>90 \%$ of women experience retrograde menstruation, other molecular factors must have a role to allow the survival and growth of endometrial tissue in menstrual debris outside of the uterus. ${ }^{5-8}$

High estrogen production is a consistently observed endocrine feature of endometriosis. The disease entities develop in women of reproductive age and regress after menopause, therefore suggesting its estrogen-dependent nature. The hormone-dependent nature of the disease led to research on local estrogen production, with a major focus on the expression of cytochrome P450 aromatase. ${ }^{9}$ Reports indicate that increased expression of CYP19 aromatase occurs in ectopically located endometriotic lesions, especially ovarian endometriomas. ${ }^{10}$ CYP19 aromatase expression has also been detected in the eutopic endometrium of women with other uterine diseases, such as leiomyoma and adenomyosis. ${ }^{11}$

As one severe complication of endometriosis, infertility is thought to occur because tubal anatomy or function is impaired, egg and embryo quality suffer and rates of

Department of Gynecology and Obstetrics, The 2nd Affiliated Hospital of the Wenzhou Medical University, Wenzhou, China

Correspondence: Professor J Lv, Department of Gynecology and Obstetrics, The 2nd Affiliated Hospital of the Wenzhou Medical University, 109 Xue Yuan Xi Lu, Wenzhou, Zhejiang Province 325027, China.

E-mail: jieqlv@gmail.com

Received 3 December 2013; revised 10 February 2014; accepted 27 February 2014 
implantation decrease. ${ }^{6}$ It has been proposed that the expression of aromatase has a key role in the development of endometriosis and endometriosis-related infertility. ${ }^{12}$ A gene expression profiling study conducted in 2003 reported that the aromatase gene is associated with endometriosis-induced implantation failure and infertility. ${ }^{13}$

In addition to aberrations in estrogen production and metabolism, genetic background has also been linked to the risk of endometriosis. Relatives of women with the disease are seven times more likely to also be afflicted than are the relatives of disease-free women. ${ }^{14}$ Evidence from studies shows that endometriosis may be inherited in a polygenic manner. ${ }^{15-17}$ Because genetic factors have important roles in the pathogenesis of infertility, identifying the genetic factors involved in the development of infertility is essential for the early prediction and prevention of infertility.

In 2010, a genome-wide association study located an endometriosis-associated locus on 9p21 in the Japanese population; later, another genome-wide association study reported a locus at 7p15.2 associated with endometriosis in Australian and UK populations. ${ }^{18,19}$ Studies during the latest decade have focused on the genes encoding enzymes involved in the estrogen biosynthesis process. ${ }^{20,21}$ In the studies mentioned above, distinct gene loci and genes were reported to be associated with susceptibility to endometriosis in different populations. This difference may be caused by racial heterogeneity; however, it also indicates that genetic susceptibility to endometriosis is controlled by multiple loci and gene polymorphisms.

Aromatase cytochrome P450 (encoded by the CYP19 gene) is the key enzyme in humans that synthesizes the conversion of androstenedione and testosterone to estrone and E2, respectively. Furthermore, the aromatase cytochrome P450 is involved in the final and rate-limiting step of estrogen synthesis and has been associated with circulating estrogen levels. ${ }^{22}$ Although endometriotic implants express aromatase, endometrial tissue from uterine-disease-free women does not exhibit aromatase activity. In contrast, aromatase enzyme activity and increased mRNA levels are readily detectable in endometriosis. ${ }^{23-25}$

The CYP19 gene is located on chromosome 15q21.2. Several single-nucleotide polymorphisms have been linked to other estrogen-dependent diseases, such as uterine myoma, endometriosis, breast cancer and endometrial cancer. ${ }^{26-29}$ Thus far, however, the results from studies on the association between CYP19 gene polymorphisms and endometriosis are inconsistent as a result of the sample sizes of the investigated populations of the different studies. To our knowledge, reports of this nature have yet to focus on the Chinese population.

We hypothesized that polymorphisms of the CYP19 gene are associated with endometriosis, endometriosis with ovarian chocolate cysts and endometriosis-related infertility. To demonstrate this hypothesis, we conducted a case-control study in the Chinese Han population to evaluate the association of polymorphisms in rs2236722:T $>C \quad(115 \mathrm{~T}>\mathrm{C})$,
rs700518:A $>$ G $(240 A>G)$ and rs10046:T $>C \quad(1531 T>C)$ and $[$ TTTA $] n$ tetranucleotide repeat polymorphisms with endometriosis, chocolate cysts and infertility.

\section{MATERIALS AND METHODS}

\section{Subjects}

This study was approved by the institutional review board of Wenzhou Medical University and performed in accordance with the World Medical Association Helsinki Declaration. Informed consent was obtained from all participants.

A total of 146 female patients diagnosed with endometriosis and 225 healthy control subjects were recruited into this case-control study. The endometriosis patients were recruited at the Department of Obstetrics and Gynecology, the 2nd Affiliated Hospital of the Wenzhou Medical University, Wenzhou, China from 2009 July to May 2011. The patients had been laparoscopically and histologically diagnosed with endometriosis and confirmed as with/without chocolate cysts or adenomyosis. Subjects with osteoporosis, pregnancy, breast cancer, myoma, endometrial cancer or other gynecological tumors were excluded. Women with endometriosis who did not achieve pregnancy after at least six natural or induced cycles following laparoscopy were considered infertile. All women whose partners had any male factors associated with infertility were excluded from the study. Among the 146 endometriosis patients, 94 were laparoscopically and histologically diagnosed with chocolate cysts, and 65 were confirmed to be infertile. The healthy fertile control group was selected from individuals receiving regular checkups in the outpatient clinic. All of the subjects were from the Chinese Han population.

\section{Genotyping}

Genomic DNA was extracted from peripheral blood using the GFXTM kit (Amersham Pharmacia Biotech, Piscataway, NJ, USA) in accordance with the manufacturer's instructions.

Four CYP19 polymorphisms sites were selected in public databases (http://www.ncbi.nlm.nih.gov/snp/), including rs2236722:T >C, rs700518:A $>$ G, rs10046:T $>C$ and [TTTA]n tetranucleotide repeat polymorphisms. CYP19 rs2236722 polymorphisms were genotyped with a PCR method by confronting two-pair primers, as reported by Hirose et al. ${ }^{26}$ in 2004. Briefly, genomic DNA was amplified by two pairs of primers, forward 1: $5^{\prime}$-ATCTGTACTGTACAGCACC- $3^{\prime}$ and reverse 1: $5^{\prime}$-ATGTGCCCTCATAATTCCG- $3^{\prime}$ for the C (Arg) allele and forward 2: $5^{\prime}$-GGCCTTTTTCTCTTGGTGT- $3^{\prime}$ and reverse 2: $5^{\prime}$-CTCCAAGTCCTCATTTGCT-3' (Bioneer, Seoul, Korea), for the $\mathrm{T}$ (Trp) allele. The PCR products were further subjected to $2 \%$ agarose gel electrophoresis, and the alleles were identified as follows: the $\mathrm{T}$ allele was represented by DNA bands with sizes of 200 and $427 \mathrm{bp}$; the C allele was represented by DNA bands with sizes of 264 and $427 \mathrm{bp}$; and the heterozygote displayed a combination of bands (427, 264 and 200 bp, shown in Figure 1a).

CYP19 rs700518 genotyping was performed by PCR-restriction fragment length polymorphism. Genomic DNA was amplified using the following primers: forward, $5^{\prime}$-AGTAACACAGAACAGTTGCA-3'; and reverse, $5^{\prime}$-TCCAGACTCGCATGAATTCTCCGTA- $3^{\prime}$ and subjected to digestion with the restriction enzyme RsaI. Genotypes were identified by a single band of $188 \mathrm{bp}$ for AA, a band of $164 \mathrm{bp}$ for GG and double bands of 164 and $188 \mathrm{bp}$ for $A G$ (shown in Figure $1 \mathrm{~b})$.

CYP19 rs10046 genotyping was also performed by PCR-restriction fragment length polymorphism. Genomic DNA was amplified by 

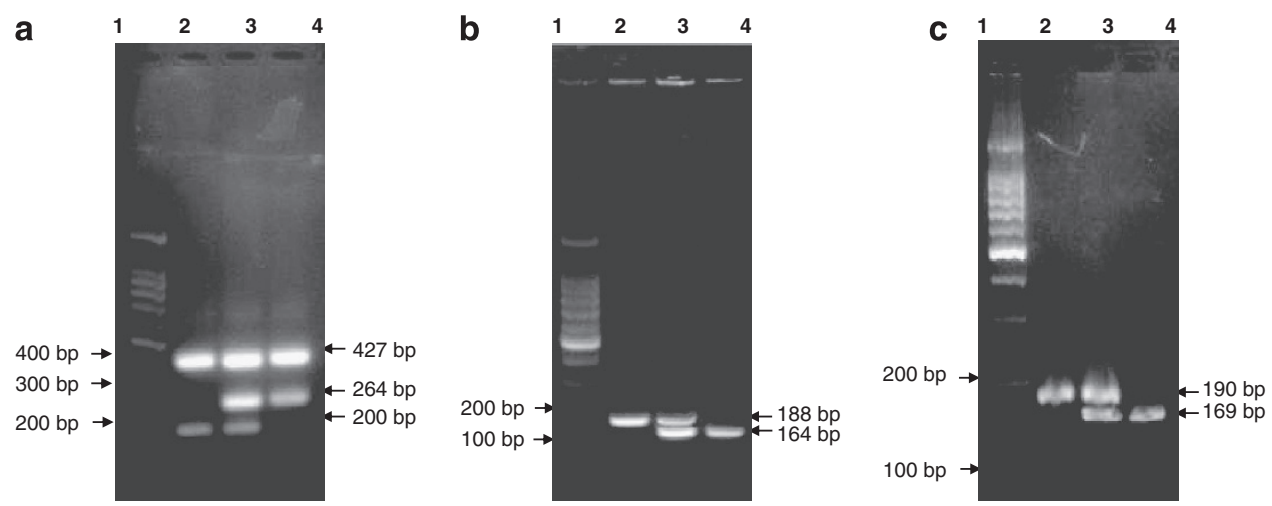

Figure 1 Images of CYP19 polymorphism genotyping. (a) Genotyping of CYP19 rs2236722:T>C: lane 1, DNA ladder; lane 2, TT genotype (427 and $200 \mathrm{bp}$ ); lane 3, TC genotype (427, 264 and $200 \mathrm{bp}$ ); lane 4, CC genotype (427 and $264 \mathrm{bp}$ ). (b) Genotyping of rs700518:A>G: lane 1, DNA ladder; lane 2, AA genotype (188bp); lane 3, AG genotype (188 and 164 bp); lane 4, GG genotype (164 bp). (c) Genotyping of CYP19 rs10046:T>C: lane 1, DNA ladder; lane 2, TT genotype (190 bp); lane 3, TC genotype (190 and $169 \mathrm{bp})$; lane 4, CC genotype (169 bp).

primers, forward, 5'-TAGAGAAGGCTGGTCAGTGCC-3' and reverse, $5^{\prime}$-CTCTGGTGTGAACAGGAGCA-3', followed by digestion with Bsp1286I. The TT genotype was indicated by a single band of $190 \mathrm{bp}$, the CC genotype was indicated by a single band of $169 \mathrm{bp}$, and the TC genotype was indicated by the presence of two visible bands, that is, both 169 and 190 bp (shown in Figure 1c).

CYP19 [TTTA]n site polymorphism was genotyped according to the PCR product size. A fragment containing [TTTA]n alleles was first amplified by primers (forward 5'-GCAGGTACTTAGTTAGCTAC- $3^{\prime}$ and reverse $5^{\prime}$-TTACAGTGAGCCAAGGTCGT- $3^{\prime}$ ) and then subjected to 8 and $10 \%$ polyacrylamide gels, respectively, followed by silver staining. The genotypes were identified by ultraviolet densitometry.

All genotyping was performed in duplicate, and 100 samples were randomly selected for sequencing to further confirm the genotypes.

\section{Statistical analysis}

Statistical power and sample size were determined by the Epi Info 7 program (CDC, Atlanta, GA, USA). For differences between the patients with endometriosis/with ovarian chocolate cysts/with infertility and controls, two models were tested to compare either allelic frequencies in $2 \times 2$ contingency tables or genotypes in $2 \times 3$ contingency tables. For association estimation, odds ratios (OR) and $95 \%$ confidence intervals (CIs) were estimated from the unconditional logistic regression model. All of the analyses were performed by chi-squared analysis using the Statistical Package for the Social Sciences software (SPSS 10.0, Chicago, IL, USA). A two-tailed $P$-value of $\leqslant 0.05$ was considered statistically significant. HardyWeinberg equilibrium analysis, linkage disequilibrium (LD) and haplotype construction and analysis were performed using the SHEsis online software (Bio-X Institutes of Shanghai Jiao Tong University, Shanghai, China). ${ }^{30}$

\section{RESULTS}

\section{Demographic data of subjects}

The age of the control group ( $37.4 \pm 10.3$ years) was higher than that of the endometriosis, chocolate cyst and infertility groups $(32.5 \pm 7.4,33.7 \pm 5.5$ and $31.0 \pm 6.2$ years, respectively). The advantage of this difference was to avoid the possibility that some of the healthy controls would develop endometriosis in later years.
Distributions of CYP19 polymorphisms in the control, endometriosis, endometriosis with chocolate cyst and endometriosis-related infertility groups

In this case-control study, we recruited 225 healthy control women and 146 cases diagnosed as endometriosis; among them, there were 94 cases concurrent with chocolate cysts, 65 cases diagnosed as infertile and 34 cases with adenomyosis. Because of the extreme small sample size in the adenomyosis group, we do not report here associations of CYP19 polymorphisms with adenomyosis. Briefly, when we set the percentage of the control exposed to susceptible genotype as $70 \%$, with an OR of 2 , the sample size of 225 control subjects and 146 cases can reach $78 \%$ statistical power (Table 1).

Four CYP19 gene single-nucleotide polymorphisms, rs2236722:T > C, rs700518:A > G, rs10046:T >C and [TTTA]n tetranucleotide repeat polymorphisms, were selected for genotyping. To simplify the further analysis, we classified the [TTTA]n alleles into Short type and Long type according to the number of repeats: S (Short), up to 7 repeats; and L (Long), 8-11 repeats. The distributions of rs2236722, rs700518, rs10046 and [TTTA]n did not deviate from Hardy-Weinberg equilibrium, with the $P$-values shown in Table 1.

The frequency distributions of genotypes in rs2236722, rs700518, rs10046 and [TTTA]n were not significantly different between the control group and endometriosis group or endometriosis with chocolate cysts group (Table 1). A comparison of the control group and endometriosis with infertility group showed that polymorphisms in the rs2236722, rs 10046 and [TTTA]n sites were not related to the risk of endometriosis-related infertility.

Interestingly, however, we observed that the frequency of the rs700518 AA genotype in the endometriosis-related infertility group was significantly higher than that in the control group (55.4 vs $25.3 \%$ ), whereas the frequency of the AG genotype in the infertility group was much lower than in the control group $(21.5$ vs $55.6 \%)(P<0.001)$. We analyzed the frequency distributions by two different genetic models, A allele recessive 
Table 1 Distribution of frequency of alleles and genotypes in case and control groups

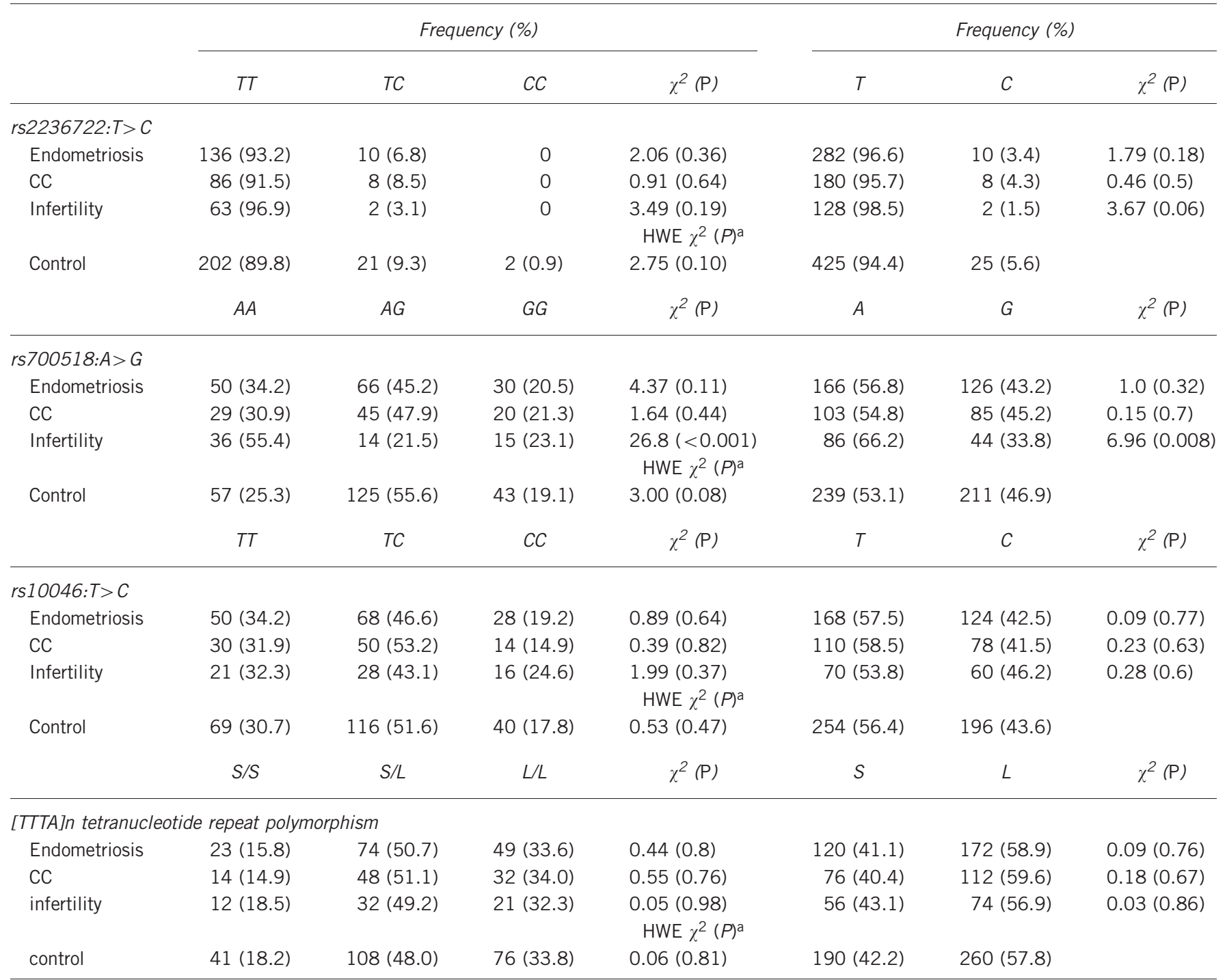

Abbreviations: CC, chocolate cyst; HWE, Hardy-Weinberg equilibrium.

aHWE $\chi^{2}(P)$, Hardy-Weinberg equilibrium analysis. $\chi^{2}$ and $P$-value based on the control group.

Table 2 The association of rs700518:A $>$ G polymorphisms with the risk of endometriosis-related infertility

\begin{tabular}{|c|c|c|c|c|c|c|}
\hline Model/type & & Infertility $^{a}$ & Control & $\chi^{2}(P)$ & OR $(95 \% \mathrm{Cl})$ & Power \\
\hline \multirow[t]{2}{*}{ A allele recessive } & $A A$ & $36(55.4)$ & $57(25.3)$ & $20.8(<0.001)$ & $3.66(2.06-6.50)$ & $96 \%$ \\
\hline & $A G+G G$ & $29(44.6)$ & $168(74.7)$ & & & \\
\hline & $\mathrm{GG}$ & $15(23.1)$ & $43(19.1)$ & & & \\
\hline Allele & $A$ & $86(66.2)$ & $239(53.1)$ & $6.96(0.008)$ & $1.73(1.15-2.59)$ & $71 \%$ \\
\hline
\end{tabular}

Abbreviations: $\mathrm{Cl}$, confidence interval; OR, odds ratio.

a Values in the table show number of individuals (frequency percentage).

bStatistical power

and A allele dominant models, as shown in Table 2. The most frequent genotype in the control group was the AG genotype; in the infertility group, the AG genotype frequency was significantly decreased, and, instead, AA was apparently increased, indicating the effect of the A allele in the recessive form. Under the recessive model of the A allele, the rs700518 AA genotype was found to be significantly associated with an increased risk of endometriosis-related infertility 
Table 3 Linkage disequilibrium between rs2236722:T $>C$, rs700518:A $>$ G, rs10046:T $>C$ and [TTTA]n tetranucleotide repeat polymorphism

\begin{tabular}{|c|c|c|c|}
\hline$D^{\prime}\left(R^{2}\right)$ & rs700518:A>G & $r s 10046: T>C$ & [TTTA]n \\
\hline \multicolumn{4}{|l|}{ Control } \\
\hline rs2236722:T>C & $0.66(0.02)$ & $0.43(0.01)$ & $0.13(0.001)$ \\
\hline rs10046:T>C & - & - & $0.06(0.001)$ \\
\hline rs700518:A>G & - & $1.0(0.56)$ & $0.44(0.11)$ \\
\hline rs10046:T >C & - & - & $0.46(0.11)$ \\
\hline \multicolumn{4}{|c|}{ Endometriosis with chocolate cyst } \\
\hline rs2236722:T>C & $0.99(0.04)$ & $0.99(0.06)$ & $0.99(0.05)$ \\
\hline rs700518:A>G & - & $1.0(0.59)$ & $0.45(0.12)$ \\
\hline rs2236722:T>C & $1(0.008)$ & $1(0.02)$ & $1(0.02)$ \\
\hline rs700518:A>G & - & $1(0.44)$ & $0.76(0.22)$ \\
\hline rs10046:T>C & - & - & $0.63(0.35)$ \\
\hline
\end{tabular}

(OR (95\% CI): 3.66 (2.06-6.50)). The rs700518 A allele was significantly associated with increased infertility risk in the endometriosis population ( 66.2 vs $53.1 \%$ in the infertility and control groups, respectively, OR (95\% CI): 1.73 (1.15-2.59), $P<0.01)$.

According to the exposure frequency of the AA genotype in the infertility group and the OR, a sample size of 65 infertility cases and 225 control subjects reaches approximately $96 \%$ statistical power.

\section{LD and haplotype distribution analysis}

The combination of D' and $R^{2}$ values showed that there was no LD in the control group (D', $0.4 ; R^{2}, 0.01$ ), whereas LD between rs700518:A>G and rs10046:T $>C$ was evident although not significantly significant (D, $\left.1.0 ; R^{2}, 0.56\right)$ in the endometriosis group, as shown in Table 3. No significant LD was found between the other tested sites.

We further analyzed the distribution of haplotypes constituting rs700518:A $>$ G and rs10046:T $>C$, as shown in Table 4. Accordingly, we observed that the rs700518-rs10046 haplotypes AC and GT existed with increased frequency in the endometriosis case group than in the normal control group (42.5 and $43.2 \%$ vs 30.5 and $33.9 \%$ ).

\section{DISCUSSION}

Through this case-control study, we observed that the tested CYP19 polymorphisms (rs2236722: $\mathrm{T}>\mathrm{C}$, rs700518:A $>\mathrm{G}$, rs10046:T $>$ C and [TTTA]n tetranucleotide repeat) were not significantly associated with the risk of endometriosis or endometriosis with ovarian chocolate cysts. However, the CYP19 rs700518 AA genotype was significantly associated with
Table 4 Associations of haplotypes constituting of rs700518:A $>G$ and rs10046:T $>C$ with risk of endometriosis

\begin{tabular}{lcccc}
$240-$ & & & & \\
1153 & Endometriosis & Control & $\chi^{2}(P)$ & OR $(95 \% \mathrm{Cl})$ \\
\hline AC & $124(42.5)$ & $137(30.5)$ & $11.06(<0.001)$ & $1.68(1.24-2.28)$ \\
AT & $42(14.4)$ & $102(22.6)$ & $7.62(0.006)$ & $0.58(0.39-0.86)$ \\
GC & 0 & $58(13.0)$ & $41.30(<0.001)$ & \\
GT & $126(43.2)$ & $152(33.9)$ & $6.52(0.01)$ & $1.48(1.10-2.01)$
\end{tabular}

Abbreviations: $\mathrm{Cl}$, confidence interval; OR, odds ratio.

the increased risk of endometriosis-related infertility in a recessive form of the A allele.

This is the first report in the Chinese Han population investigating the association of CYP19 gene polymorphisms with the susceptibility to endometriosis and related complications, such as chocolate cysts and infertility. We strictly limited the study population to the Chinese Han population in the southern region to maintain genetic homogeneity among the subjects and also to avoid the confounding effects from interracial differences of genetic backgrounds and environmental factors, such as living behaviors. Although only 65 infertile subjects were recruited in this present study, the number still reaches $>90 \%$ statistical power under this current circumstance.

Our study shows that CYP19 gene polymorphisms are not associated with endometriosis or endometriosis-related chocolate cysts in Chinese women. These results are consistent with several previous studies from Korean, ${ }^{31}$ Japanese $^{32}$ and Caucasian populations, ${ }^{20}$ all of which reported no significant 
association of CYP19 gene polymorphisms with the risk of endometriosis or chocolate cysts. Taken together, the CYP19 gene can be excluded as a genetic biomarker of endometriosis or endometriosis-related chocolate cysts.

Interestingly, in this current study, we found that CYP19 rs700518 AA was associated with the risk of endometriosisrelated infertility in the Chinese population. It was previously reported in the Brazilian population that polymorphisms in the nuclear factor- $\mathrm{\kappa B}$ gene promoter, $\mathrm{B}$ lymphocyte stimulator gene promoter and TYK2 were associated with endometriosisrelated infertility. ${ }^{33-35}$ Nevertheless, we report here for the first time that in the Chinese Han population the CYP19 rs700518 AA genotype is associated with endometriosis-related infertility. This result indicates clinical relevance with regard to two aspects.

First, CYP19 rs700518:A $>\mathrm{G}$ might be located in a haplotype block contributing to a genetic susceptibility of endometriosis-related infertility and is therefore a biomarker of early diagnosis and prevention of infertility caused by endometriosis. Moreover, we observed a higher degree of LD between rs700518 and rs10046 in the endometriosis case group than in the control group, suggesting that this region contains a susceptible gene for endometriosis.

However, the genotype associated with disease susceptibility may have biological significance in pathogenesis by affecting the gene expression level. There are a series of data available. The rs700518AA genotypes were reported to be associated with some other estrogen-related diseases, such as hypertension $^{36}$ and breast cancer. ${ }^{37}$ Although CYP19 rs700518A $>\mathrm{G}$ is an anonymous variation in exon 3 (Val $80 \mathrm{Val}$ ), it may affect posttranscriptional modification, resulting in changes in gene expression and aromatase levels and further affecting estrogen production. Several studies demonstrate that serum estrogen levels affect female fertility or the outcome of in vitro fertilization. ${ }^{38-40}$ Riancho et al. ${ }^{41}$ reported evidence of differential allelic expression: in heterozygous individuals, transcripts bearing $A$ alleles at rs700518:A $>G$ singlenucleotide polymorphism were less abundant than those with the alternative $G$ alleles, and total aromatase expression was four times lower in fat samples from individuals with the AA genotype than in those with the GG genotype. Another study has reported that the AA genotype was significantly associated with decreased 17-beta estradiol serum levels in male subjects. ${ }^{42}$ Moreover, evidence from a study suggested that a lower estradiol level is associated with a low likelihood of successful clinical pregnancy after the use of assisted reproduction techniques. ${ }^{38}$ These studies indicated that an association of the rs700518AA genotype with endometriosisrelated infertility is caused by an alteration in the CYP19 gene expression level and is therefore involved in the pathogenesis of endometriosis-related infertility.

Another interesting observation was that in the [TTTA]n tetranucleotide repeat polymorphism site, the 11/11 genotypic frequency in adenomyosis was significantly lower than that in the control group; accordingly, the 7/11 genotype was increased in the adenomyosis group compared with the control group (data not shown). However, this study recruited only 34 cases diagnosed as adenomyosis, which is too small to represent a sample size, and thus it is not possible to draw any conclusion from these data. Although adenomyosis and leiomyomas are separate entities from endometriosis, they share a common pathophysiology in that their growth is estrogen dependent, with the expression of both estrogen receptors and aromatase, and they have a complicated pattern of occurrence. ${ }^{43}$ At this point, it is worthy to pursue the association of [TTTA]n polymorphisms with adenomyosis in the future.

Our future work will focus on two series of studies. First, we will initiate a multi-center investigation to recruit more cases, including endometriosis with chocolate cysts, infertility, and adenomyosis, as well as further strengthening the evidence of genetic involvement in the pathogenesis of endometriosis-related chocolate cysts, infertility and adenomyosis. In addition, it is necessary to investigate the biological function of rs700518AA. We plan to measure the individual serum estradiol level and analyze whether the rs700518:A $>$ G polymorphism affects the serum estradiol level in patients. Once this association is confirmed by biological significance and explained through functional studies, this polymorphism could become a potential target for the early prevention and treatment of endometriosisrelated infertility.

\section{ACKNOWLEDGEMENTS}

We thank all the subjects involved in this study. This study is supported by the Wenzhou Science and Technology Bureau (Grant No. Y20080119).

1 Bulun SE. Endometriosis. New Engl J Med 2009; 360: 268-279.

2 Giudice LC, Kao LC. Endometriosis. Lancet 2004; 364: 1789-1799.

3 Guzick DS, Silliman NP, Adamson GD, Buttram VCJ, Canis M, Malinak LR et al. Prediction of pregnancy in infertile women based on the American Society for Reproductive Medicine's revised classification of endometriosis. Fertil Steril 1997; 67: 822-829.

4 Sampson JA. Peritoneal endometriosis due to the menstrual dissemination of endometrial tissue into the peritoneal cavity. Am J Obstet Gynecol 1927; 14: 422-469.

5 Bulun SE, Monsavais D, Pavone ME, Dyson M, Xue Q, Attar E et al. Role of estrogen receptor $\beta$ in endometriosis. Semin Reprod Med 2012; 30: $39-45$.

6 Halme J, Becker S, Hammond MG, Raj MHG, Raj S. Increased activation of pelvic macrophages in infertile women with mild endometriosis. Am J Obstet Gynecol 1983; 145: 333-337.

7 Dmowski WP, Steele RW, Baker GF. Deficient cellular immunity in endometriosis. Am J Obstet Gynecol 1981; 141: 377-383.

8 Li X, Gong X, Zhu L, Leng J, Fan Q, Sun D et al. Stretch magnitudeand frequency-dependent cyclooxygenase 2 and prostaglandin E2 up-regulation in human endometrial stromal cells: possible implications in endometriosis. Exp Biol Med (Maywood) 2012; 237: 1350-1358.

9 Rhee HS, Oh SH, Ko BJ, Han DM, Jeon BH, Park H et al. Expression of 3beta-hydroxysteroid dehydrogenase and P450 side chain cleavage enzyme in the human uterine endometrium. Exp Mol Med 2003; 35: $160-166$

10 Bukulmez O, Hardy DB, Carr BR, Auchus RJ, Toloubeydokhti T, Word RA et al. Androstenedione up-regulation of endometrial aromatase expression via local conversion to estrogen: potential relevance to the pathogenesis of endometriosis. J Clin Endocrinol Metab 2008; 93: 3471-3477. 
11 Wölfler MM, Nagele F, Kolbus A, Seidl S, Schneider B, Huber JC et al. A predictive model for endometriosis. Hum Reprod 2005; 20: $1702-1708$

12 Maia HJ, Casoy J, Valente Filho J. Is aromatase expression in the endometrium the cause of endometriosis and related infertility? Gynecol Endocrinol 2009; 25: 253-257.

13 Kao LC, Germeyer A, Tulac S, Lobo S, Yang JP, Taylor RN et al. Expression profiling of endometrium from women with endometriosis reveals candidate genes for disease-based implantation failure and infertility. Endocrinology 2003; 144: 2870-2881.

14 Simpson JL, Elias S, Malinak LR, Buttram VC Jr. Heritable aspects of endometriosis. I. Genetic studies. Am J Obstet Gynecol 1980; 137: 327-331.

15 Moen MH, Magnus P. The familial risk of endometriosis. Acta Obstet Gynecol Scand 1993; 72: 560-564.

16 Xu S, Wu W, Sun H, Lu J, Yuan B, Xia Y et al. Association of the vascular endothelial growth factor gene polymorphisms $(-460 \mathrm{C} / \mathrm{T},+405 \mathrm{G} / \mathrm{C}$ and +936T/C) with endometriosis: a meta-analysis. Ann Hum Genet 2012; 76: 464-471.

17 Barbosa CP, Teles JS, Lerner TG, Peluso C, Mafra FA, Vilarino FL et al. Genetic association study of polymorphisms FOXP3 and FCRL3 in women with endometriosis. Fertil Steril 2012; 97: 1124-1128.

18 Uno S, Zembutsu H, Hirasawa A, Takahashi A, Kubo M, Akahane T et al. A genome-wide association study identifies genetic variants in the CDKN2BAS locus associated with endometriosis in Japanese. Nat Genet 2010; 42: 707-710.

19 Painter JN, Anderson CA, Nyholt DR, Macgregor S, Lin J, Lee SH et al. Genome-wide association study identifies a locus at 7 p15.2 associated with endometriosis. Nat Genet 2011; 43: 51-54.

20 Trabert B, Schwartz SM, Peters U, De Roos AJ, Chen C, Scholes D et al. Genetic variation in the sex hormone metabolic pathway and endometriosis risk: an evaluation of candidate genes. Fertil Steril 201 1; 96: 1401-1406.

21 Li Y, Liu F, Tan SQ, Wang Y, Li SW. Estrogen receptor-alpha gene Pvull $(\mathrm{T} / \mathrm{C})$ and $\mathrm{Xbal}(\mathrm{A} / \mathrm{G})$ polymorphisms and endometriosis risk: a metaanalysis. Gene 2012; 508: 41-48.

22 Gruber CJ, Tschugguel W, Schneeberger C, Huber JC. Production and actions of estrogens. New Engl J Med 2002; 346: 340-352.

23 Kitawaki J, Kusuki I, Koshiba H, Tsukamoto K, Fushiki S, Honjo H. Detection of aromatase cytochrome P-450 in endometrial biopsy specimens as a diagnostic test for endometriosis. Fertil Steril 1999; 72: 1100-1106.

24 Bulun SE, Fang Z, Imir G, Gurates B, Tamura M, Yilmaz B et al. Aromatase and endometriosis. Semin Reprod Med 2004; 22: 45-50.

25 Bulun SE, Imir G, Utsunomiya H, Thung S, Gurates B, Tamura M et al. Aromatase in endometriosis and uterine leiomyomata. J Steroid Biochem Mol Biol 2005; 95: 57-62.

26 Hirose K, Matsuo K, Toyama T, Iwata H, Hamajima N, Tajima K. The CYP19 gene codon 39 Trp/Arg polymorphism increases breast cancer risk in subsets of premenopausal Japanese. Cancer Epidemiol Biomarkers Prev 2004; 13: 1407-1411.

27 Xu WH, Dai Q, Xiang YB, Long JR, Ruan ZX, Cheng JR et al. Interaction of soy food and tea consumption with CYP19A1 genetic polymorphisms in the development of endometrial cancer. Am J Epidemiol 2007; 166: $1420-1430$

28 Haiman CA, Hankinson SE, Colditz GA, Hunter DJ, De Vivo I. A polymorphism in CYP17 and endometrial cancer risk. Cancer Res 2001; 61: 3955-3960.

29 Shin A, Kang D, Choi JY, Lee KM, Park SK, Noh DY et al. Cytochrome P450 1A1 (CYP1A1) polymorphisms and breast cancer risk in Korean women. Exp Mol Med 2007; 39: 361-366.

30 Shi YY, He L. SHEsis, a powerful software platform for analyses of linkage disequilibrium, haplotype construction, and genetic association at polymorphism loci. Cell Res 2005; 15: 97-98.
31 Hur SE, Lee S, Lee JY, Moon HS, Kim HL, Chung HW. Polymorphisms and haplotypes of the gene encoding the estrogen-metabolizing CYP19 gene in Korean women: no association with advanced-stage endometriosis. J Hum Genet 2007; 52: 703-711.

32 Kado N, Kitawaki J, Obayashi $\mathrm{H}$, Ishihara $\mathrm{H}$, Koshiba $\mathrm{H}$, Kusuki I et al. Association of the CYP17 gene and CYP19 gene polymorphisms with risk of endometriosis in Japanese women. Hum Reprod 2002; 17: 897-902.

33 Bianco B, Lerner TG, Trevisan CM, Cavalcanti V, Christofolini DM, Barbosa CP. The nuclear factor-kB functional promoter polymorphism is associated with endometriosis and infertility. Hum Immunol 2012; 73: 1190-1193.

34 Peluso C, Christofolini DM, Goldman CS, Mafra FA, Cavalcanti V, Barbosa CP et al. TYK2 rs34536443 polymorphism is associated with a decreased susceptibility to endometriosis-related infertility. Hum Immunol 2013; 74: 93-97.

35 Christofolini DM, Cavalheiro CM, Teles JS, Lerner TG, Brandes A, Bianco B et al. Promoter $-817 \mathrm{C}>\mathrm{T}$ variant of $\mathrm{B}$ lymphocyte stimulator gene (BLyS) and susceptibility to endometriosis-related infertility and idiopathic infertility in Brazilian population. Scand J Immunol 2011; 74: 628-631.

36 Ziv-Gal A, Gallicchio L, Miller SR, Zacur HA, Flaws JA. A genetic polymorphism in the CYP19A1 gene and the risk of hypertension among midlife women. Maturitas 2012; 71: 70-75.

37 Haiman CA, Dossus L, Setiawan VW, Stram DO, Dunning AM, Thomas G et al. Genetic variation at the CYP19A1 locus predicts circulating estrogen levels but not breast cancer risk in postmenopausal women.b. Cancer Res 2007; 67: 1893-1897.

38 Kondapalli LA, Molinaro TA, Sammel MD, Dokras A. A decrease in serum estradiol levels after human chorionic gonadotrophin administration predicts significantly lower clinical pregnancy and live birth rates in in vitro fertilization cycles. Hum Reprod 2012; 27: 2690-2697.

39 Keltz MD, Stein DE, Berin I, Skorupski J. Elevated progesterone-toestradiol ratio versus serum progesterone alone for predicting poor cycle outcome with in vitro fertilization. J Reprod Med 2012; 57: 9-12.

40 Elgindy EA. Progesterone level and progesterone/estradiol ratio on the day of hCG administration: detrimental cutoff levels and new treatment strategy. Fertil Steril 2011; 95: 1639-1644.

41 Riancho JA, Valero C, Naranjo A, Morales DJ, Sañudo C, Zarrabeitia MT. Identification of an aromatase haplotype that is associated with gene expression and postmenopausal osteoporosis. J Clin Endocrinol Metab 2007: 92: 660-665.

42 Peter I, Kelley-Hedgepeth A, Fox CS, Cupples LA, Huggins GS, Housman DE et al. Variation in estrogen-related genes associated with cardiovascular phenotypes and circulating estradiol, testosterone, and dehydroepiandrosterone sulfate levels. J Clin Endocrinol Metab 2008; 93: 2779-2785.

43 Heinritz W, Paasch U, Sticherling M, Wittekind C, Simon JC, Froster UG et al. Evidence for a founder effect of the germline fumarate hydratase gene mutation R58P causing hereditary leiomyomatosis and renal cell cancer (HLRCC). Ann Hum Genet 2008; 72: 35-40.

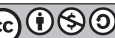

This work is licensed under a Creative Commons Attribution-NonCommercial-ShareAlike 3.0 Unported License. The images or other third party material in this article are included in the article's Creative Commons license, unless indicated otherwise in the credit line; if the material is not included under the Creative Commons license, users will need to obtain permission from the license holder to reproduce the material. To view a copy of this license, visit http://creativecommons.org/licenses/by-nc-sa/3.0/ 